\title{
Literature Review of the Interaction from FDI to IS Adjustment
}

\author{
Pan Xia ${ }^{1}$ \\ ${ }^{1}$ School of Economics and Management, Harbin \\ Engineering University, \\ Harbin, China, 150001
}

\author{
Zhou Ying-ying ${ }^{1}$ \\ ${ }^{1}$ School of Economics and Management, Harbin \\ Engineering University, \\ Harbin, China, 150001
}

\begin{abstract}
Foreign direct investment (FDI) is an important driving force of economic globalization, and with transfer of FDI in international industry; it has important influence on national industrial structure adjustment (ISA). We revolve around FDI and theme of China's IS adjustment, reviewing, analyzing and summarizing systematically main research achievements of academic literature domestically and abroad since 1990s, focusing on methods of large number of domestic existing literature and classifying their research methods, expecting to provide some clues for deeply research on this topic.
\end{abstract}

Keywords: FDI; IS; Adjustment; Research Review

\section{Introduction}

The impact of FDI on IS is not only an important theoretical problem, but also a major factor that has a profound influence on economy development of all countries. This article includes three parts, firstly, theoretical research, summarizing related international representative theories of FDI, IS; secondly, it classifies empirical research method from Chinese scholars on FDI and IS adjustment; Thirdly, review and research prospect of research results of existing literature, making comments on relevant theoretical research and empirical research of FDI and Chinese IS adjustment, pointing out its deficiencies and prospects of possible viewpoints of further study.

\section{Theory Research Review}

\subsection{Double-Gap Theory.}

With the deepening of economic globalization, international investment also has a huge impact on host country economy. In early 1960s, H. Chenery put forward the famous "double gap model", pointed out that economy development of host country lack of domestic resources, the introduction and use of FDI can help compensate for foreign exchange gap, which promote economic growth and structural transformation of host country. Then Todaro and others put forward "four gap model" according to "two gaps model", pointing that developing countries has "saving gap", "foreign exchange gap", "government tax gap", and "technical talent gap" in process of economic development, while entry of FDI to host country can help to provide "a variety of resources " to solve the above problems.

\subsection{Theory of Monopoly Advantage}

In 1960, Professor Stephen hammer from the Massachusetts institute of technology ( $\mathrm{S}$. Hymer) in his doctoral thesis point that, domestic enterprise's international business: research of FDIputting forward to monopoly advantage to explain investment behavior of foreign enterprises for the first time, posing challenges to traditional theories. After supplement from this supervisor kindle berg (C. P. Kindle Berger), this theory developed into the earliest and most influential monopoly Advantage Theory (Monopolistic Advantage going) about international direct investment.

The theory put the structure of market incompleteness and enterprise specific advantage these two basic concepts as prerequisite, pointing out that market incompleteness is root of enterprise monopoly advantage, monopoly advantage is the motivation for enterprise to carry out the FDI. Monopoly advantage theory points out that uncompleted external market put multinational company monopoly on its advantages. Uncompleted Market mainly include: Uncompleted product market; Uncompleted Factor market; Uncompleted Economies of scale and uncompleted external economic market; Uncompleted Market caused by government policy.

\subsection{Product Life Cycle Theory.}

In 1966, Harvard professor Vernon put forward product life cycle theory, pointing that foreign capital enterprise conform to changes in product life cycle, mature industry in the shift to lower-cost countries respectively caused their respective country's IS upgrade. In the stage of product innovation, technology innovation countries using its monopoly advantage to develop new products, the market competition is less fierce due to the half produced product. Thus, technology is not perfect, product is less substituted, thus production is generally in domestic; In product mature stage, technology monopoly and oligopoly market structure of the enterprise is weakened, more competitors enter, domestic imitation increase, products become mature, product price is 
falling, enterprises start to look for low cost for transnational production; In product standardization phase, enterprise monopoly advantage no longer exists, the abundant natural resources and cost advantages from the developing countries will become the best choice in the multinational company FDI, at the same time, as multinational companies gradually give up the old products, they began to search and develop the new products, continuing to maintain the monopoly advantage in the field of new technology and new product .

\subsection{International Production Compromise Theory.}

Representative theory is the dunning (1988) of international production compromise theory, this theory is made up of location advantage theory, the ownership monopoly advantage theory and the internalization theory, which is currently the most influential theory system in the international industry transfer and international investment field. The core of international production compromise theory is: the OIL pattern, the three basic elements which decide the direct investment behavior of multinational corporations are: internalization Advantage, Ownership Advantage, location advantages.

\section{Industrial Structure Theory Review.}

\subsection{Theory of the Three Industry Divisions.}

The concept of three Industries was first proposed by professor at the university of Otego in New Zealand, British economist Fisher (A. G. B. Fisher), in the book "the conflict between safety and progress" published in 1935 considering the human economic activities can be divided into three industries, namely the first Industry (Primary Industry), the second Industry (Secondary Industry) and the third Industry (the Tertiary Industry).

\subsection{Theory of IS Evolution Trend.}

As a representative theory of the IS evolution trends, the theory of Match the Clark theorem reveals the economic development of labor evolution regularity of distribution in the three industries, pointing that the theorem of labor distribution change is due to the relative income differences between industries. All of human economic activity is divided into primary industry, secondary industry and tertiary industry in theorem. After a large number of economic sample observation, Match and Clark, two economists found that with the increase of per capita national income level, labor force will shift from primary industry to secondary industry firstly, when the per capita national income level improve occurs further, labor force and then transfer to the third industry.

\subsection{IS Adjustment Theory.}

Lewis (1954) earlier revealed that due to the surplus labor force with zero marginal productivity in agriculture in the developing countries, thus shift from the agricultural surplus labor force to non-agriculture would help to cut the dual economic structure gradually. Rostow's leading department (1988) theory pointed that the change of IS has a significant impact on economic growth, and pay attention to the diffusion effect of the leading industry in economy development. Shinohara Miyohei's Two Benchmark Theory (1955) refers to the income elastic datum and the productivity rising rate benchmark. The income elastic datum demanded that accumulation was put into the industry or sector with high-income elasticity; and productivity rising benchmark is asked to accumulate into industry or sector with fastest rising productivity.

Direction of Chinese scholars on FDI research is numerous, the emphasis is different also, the representative research results and viewpoints in the study about the influence of FDI to Chinese IS adjustment are as follows:

Tang Wen-xian and Han Fu-rong (2000) put forward the three gap model according to actual situation of our country, in addition to the traditional two gap existing in our country, there is a "technological gap" also, the introduction of FDI can make up for the gap, so as to promote the upgrading of IS in our country. Wang Yueping (2002) revealed the influence of the FDI to the IS upgrading in developing countries, absorbing the latest achievements in international trade and international investment theory to develop the theory of IS upgrade.

On the influence of FDI, Yang Junlong, Zhang Yuanyuan (2004) carried on the thorough analysis about the effect of FDI on Chinese IS, thinking that the positive effect from FDI on China's IS change mainly reflects in: promoted China's IS upgrade and the development of technologyintensive industry. Jing song (2005) through the data analysis indicated that FDI increased the export fund of our country and got profit, make our export industries change from labor-intensive to capital and technology intensive , and promoted the optimization and upgrading of IS in China through export demonstration effect. Wang Jun (2006) pointed that the mechanism of FDI in our country IS optimization and upgrading mainly is: promoting the adjustment of product structure in our country; Creating and promoting the rapid growth of the emerging industry in China; Promoting the adjustment of the technology innovation activities in China. Li Zhang-chun(2007) thought that industrial connection refers to the technical and economic links between various industries: FDI through industry association effect, causing related upstream and downstream industry changes in the balance of supply and demand, spreading to other industries further through the role of the industrial chain, leading to the overall IS change. 


\section{Classification of Empirical Research Method 4.1. Empirical Research Using Various Rate Index Related To The Economic Growth.}

Before 2003, empirical studies on relationship between FDI and IS adjustment mostly used various rate index related to the economic growth, such as Song Hong. Chai Yu (1998) adopted the "strategic correlation method" and analyzed the influence on the IS benefit from foreign-funded enterprises of our country in detail, and the basic conclusion was: no matter compared with all industrial enterprises in our country, or compared with our domestic enterprises after excluding foreign-funded enterprises, the overall benefit of IS joint ventures in China are reduced, in addition, foreign-funded enterprises made IS profits down mainly by changing the IS in China. Wang Luolin, Jiang Xiao-juan, Sheng Liang (2000) pointed out that after the large multinational companies with advanced technology enter our country to make investment in China, which play a significant role in driving manufacturing IS upgrade in the study of the top 500 global investment projects in China. Jiang Xiao-juan (2002) found that multinational company's invest in China is one of the most important role is to promote the development of hightech industry in our country and greatly accelerate the upgrade of domestic IS by making a research on 127 foreign companies invested in China's.

\subsection{Empirical Research with Regression Method in Econometric.}

After 2003, most empirical study use econometric regression method to study the relationship between FDI and IS adjustment. Such as Jiang Jinfan (2004) applied Granger causality test based on China's 1978-1999 statistical data to carry on the parameter estimation and test results showed that FDI had IS effect on China's economic growth. Li Xue (2005) used Granger causality test and Engle Granger cointegration relationship test based on time series data of 1983-2003 in our country, and concluded that China's FDI had the effect of IS, but long-term stable relationship does not exist between FDI and IS change, and further to draw in FDI contribution to the change of IS, FDI contribution to the secondary industry is the largest, contribution to the first and the third industry is less. Chen Xun and Gao Yuan-dong (2006) used the time series data, adopting the modern cointegration theory, carrying on the Granger causality test for China's short - and long-term relationship between IS change and FDI, with the results show that there is a long-term twoway Granger causality relationship between China's IS and FDI. Liu Yu (2007) used the panel data model to study the relationship between the three industrial added value of industry and contract about using foreign investment in our country from 1984 to 2003 and found that FDI have a positive effect for improving the added value of the three major industries. Zhou Yan, Wang Chuanyu (2008) conducted a multifaceted research on the effect of IS transformation from FDI in China's manufacturing industry, and the result shows that to some extent, FDI does play a role of the catalyst in China's IS adjustment and upgrade; effect of IS of investment derived from other countries was greater than investment from Taiwan, Hong Kong and Macao. Xiong Hao (2012) used the panel data model to study the relationship between the three industrial added value of industry and contract about using foreign investment in our country from 1984 to 2003 and found that FDI have a different positive effect for improving the added value of the three major industries, and Granger causality between FDI and three times industry increasing was only one-way. Yang An (2013) made an empirical research on the influence of FDI on the industrial economy growth in China by using the time series data on FDI and the industrial added value of different industries from 1990-2011, using measurement tools such as VAR model, co-integration test, error correction model (VEC), and the result showed: the industry growth mainly benefited from the economic growth of inertia and the influence of FDI on the industry economic growth effect was different.

\section{Review of Current Literature Research}

Theoretical study of FDI and IS adjustment, mainly based on theory of industry economics under the perspective of FDI, studying on the influence mechanism of FDI to IS are fully confirmed that FDI can promote the optimization of IS pattern. The main theoretical achievements of FDI to the influence of IS mechanism mainly through the following ways: the industry's role of linked effort before and after; technology transfer and diffusion; the effect on demonstration and competition.

Empirical studies of FDI and Chinese ISA is through statistics and econometric analysis method to study the choice of industry and organization operation of multinational companies in the region, and mainly uses various ratio index associated with economic growth and econometric regression method in empirical research for empirical research, the key is studying whether foreign capital promotes the optimization of IS adjustment or raise the international competitiveness of the industry. Almost all the results show that FDI influenced our countries IS, on the whole, it is positive effect, and the specific impacts on the three major industries are different.

\section{CONCLUSIONS}

FDI structure changing and its impact on economic growth are defined as IS effect of FDI. Whether it can promote economic growth as a standard measuring effects on IS adjustment brought by FDI, integrating theoretical basis and the research results, on one hand, carries on a theory analysis micro mechanism of the effect of FDI in the IS from the point of technology, industry correlation function before and after IS effect, effect on the growth of the industry, on the 
other hand, making a empirical analysis of FDI and industry structure effect through Chinese data to put forward corresponding proposals.

\section{Acknowledgments}

This paper supported by the National Foundation (71373059, Research on the evolution of industrial structure based on the self- organization), Fundamental Research Fund for the Central Universities.

\section{References}

[1]. Tang Wenxian Han Furong. Three Gap Model: Correction of Double Gap Model. Journal of Contemporary Economic Science, Vol. 5(2000), p.36 to-40

[2]. Wang Yueping. Our Country IS Adjustment and Upgrading Strategy: Multi-Level Development, A Variety Of Modes Coexist. Economic Research References Vol.4 ( 2002), p.84

[3]. Yang Junlong Zhang Yuanyuan. FDI and IS Adjustment in China. Journal of Macroeconomic Management Vol.20 (2004), p.7

[4]. Song Jing. The Influence of FDI No Our Country'S IS, Foreign Trade Analysis. Journal of International Trade Issues, Vol.4 (2005), p.82-86. 